\title{
A Network behind Coffee
}

\author{
Liliana Bravo-Monroy*
}

\begin{abstract}
Alumnus of Centre for Agri-Environmental Research, School of Agriculture, Policy and Development, University of Reading, UK
\end{abstract}

\section{Introduction}

Small-scale family farmers throughout the world have long struggled with the dilemmas of disparity between international coffee prices and producers' profits. Drawing on a case study conducted on perceptions of coffee productivity in a coffee-producing area of Colombia in 2010-11 (Ocamonte, Santander area), I examine the role of human and non-human actors in completing the journey of coffee from crop to cup. This article explores key actors involved in coffee production systems, social circuits and markets, highlighting the importance of connections between growers acting at local scales and people who are distant at international scales e.g., intermediaries, processors, traders, and consumers. Thus, point out the most relevant issues by understanding the underlying complexity of relationships linked to coffee productivity and profitability at farm scales interacting with global scales.

Based on field observations and interviews to coffee farmers in combination with a review of bibliographic references, here I develop a network (Figure 1) of how farmers are articulated into trade and market relations which lie well beyond the boundaries of their local agroecosystems [1]. Ethnography was used for gathering empirical data with the aim of describing people in relation to their environment [2]. It consists of the processes and products of research that documents what people know, feel, and do in a way that places those events at specific times in the history of individual lives, including pertinent global phenomena and processes $[2,3]$. Two ethnographic methods were implemented: first, semi-structured interviews with 14 smallscale coffee farmers, eight produced organic coffee and six grew conventional coffee.

Organic farms were certified by two particular seals corresponding to "Fair Trade" and an additional accreditation granted by a formal agency (BCS Öko-Garantie). Organic farms produce coffee without the use of synthetic fertilizers and pesticides. Interviewees included two organic farmers who played a key role in the start of organic production in the study area. Participants included nine female and five male farmers, mostly with primary education, some with secondary education. Questionnaires involved flexible questions in the sense that an individual could provide further explanation in case of responses with interesting/useful information. The interview protocol was designed to collect qualitative information on topics related to beliefs and attitudes about farms and management practices, their daily routines, and the role of institutions (coffee institutions, certification agencies, farmer's cooperatives) on the promotion of specific land-use practices. A second tool for gathering information was participant observation. It covered first-hand observation of daily activities related to crop management practices, farmer meetings and purchases at sale points. Moreover, informal dialogues were conducted with farmers, agriculture technicians, and local market agents.

This paper describes the role of both local factors and three key actors (i.e. growers, processors, and traders) in the development of a coffee network. That shows how local dynamics are strongly influenced by global dynamics of multiple actors. Why a coffee plantation grew where it did, has been the result not only of agroecological factors, such as crop management, climate, soil, and slope, but of market price fluctuations as well. Which crops grew in any particular place has been thus the consequence of a cumulative sequence of agroecological processes, coffee market trends and historical events.

\section{Group of Actors \#1: Growers}

A broad range of factors are involved in the production of Colombian Arabica coffee (the lower part of Figure 1) at the local scale of farms. Aspects include inter alia, insect pollination, multiple agricultural practices, beliefs and attitudes, and environmental issues that affect cherry growth and maturation (e.g. increased incidence of diseases or pests due to prolonged drought or rain, which trigger practices to minimize the impacts). For many farmers, an institutional actor (National Federation of Coffee Growers of Colombia - FNC) has played a crucial role providing coffee-growing technical assistance for improving coffee crops. Through FNC's efforts

*Corresponding author: Liliana Bravo-Monroy, Alumnus of Centre for Agri-Environmental Research, School of Agriculture, Policy and Development, University of Reading, UK

Accepted: September 17, 2019

Published online: September 19, 2019

Citation: Bravo-Monroy L (2019) A Network behind Coffee. J Rice Res Dev 2(1):61-65 


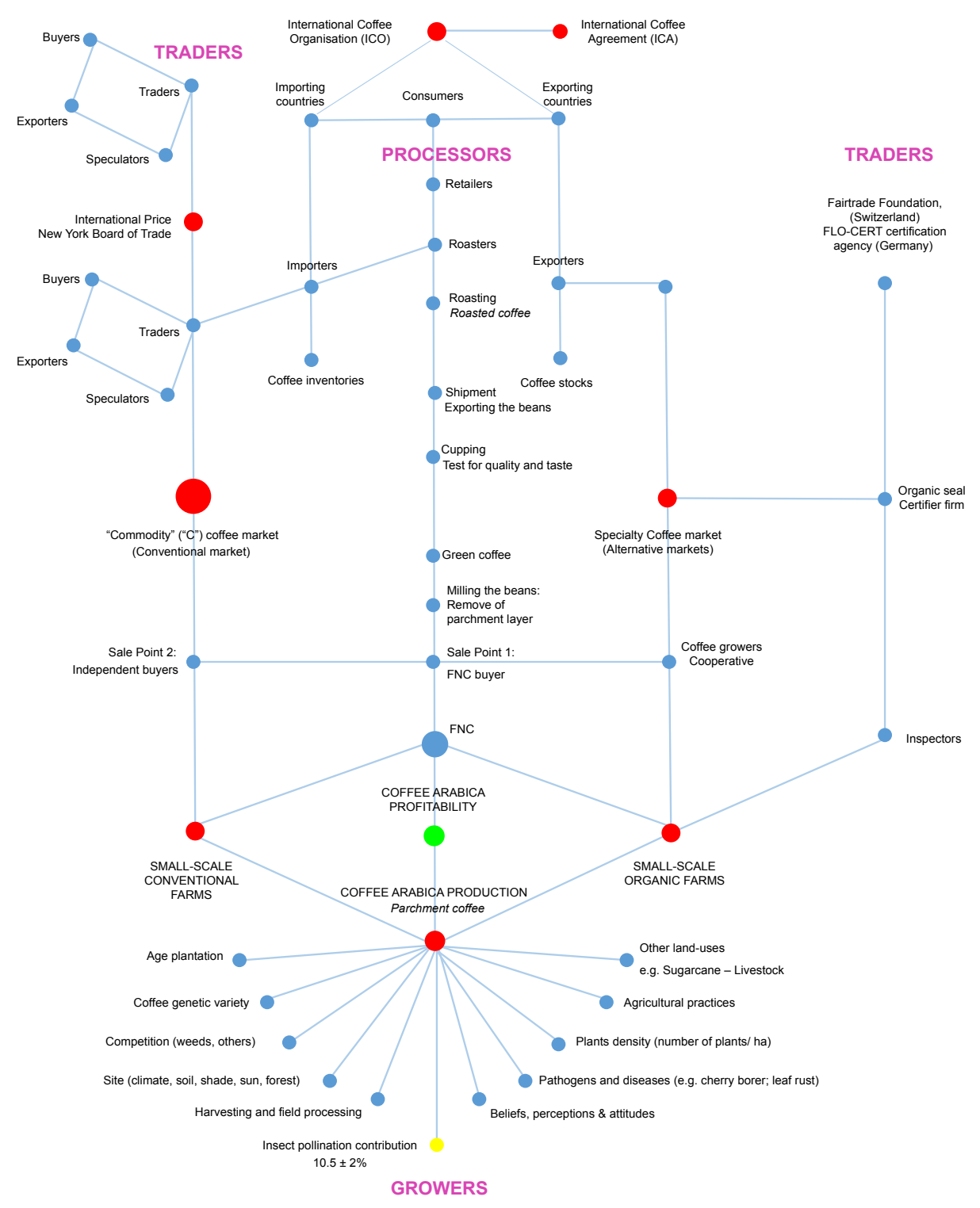

Figure 1: A network of human and non-human actors involved in coffee production, processing, trading, and consumption.

in coffee technology diffusion, credit provision and extension, coffee become an important economic activity for smallholder farmers. The FNC is an organization that has supported coffee growers on tasks related to technology adoption, extension, commercialization (local and international), processing of green beans (coffee for sell), export, and providing infrastructure to certain extent. Most of Colombian coffee growers are members of FNC, who have the option of being part of the collective bodies in municipalities and sub-regional zones. A few representatives of the national government are also members with strong influence on decision-making of FNC. Federation supports coffee growers by regulating coffee prices inside Colombia, i.e., when the international price goes down, the internal price at national level tries to keep higher as most as they can, in order to minimize losses to coffee growers. A small percentage of the total export earnings contributes to finance the FNC staff and its programs for coffee growers. From a historical perspective, in 1989 the International Coffee Agreement (ICA) disintegrated, resulting in a sharp fall of coffee prices in the international market [4]. ICA assigned export quotas to each producer country in order to keep coffee prices relatively stable [5]. The collapse of the ICA triggered the dissolution of different state-owned or parastatal coffee institutions involved in regulation of production and supply of coffee in countries such as Mexico, Guatemala, Honduras and Brazil [6]. Hence, FNC is the sole survivor coffee institution in Latin America.

In relation to attitudes, identity is a powerful organizing manifestation in social life, in the sense of belonging to affectively charged, sociable recognizable corporate coffee grower groups $[7,8]$. Furthermore, coffee growing is more than a productive activity, is an activity through which farmer express ideas, dreams and expectations. Coffee harvest is enriched by the principle of 'reciprocity', and facilitated by exchanges between family members or neighbors.

Farmers reach the final stage of coffee harvesting and field processing by using a wet method of coffee beans. 
Afterwards parchment coffee is sold into the local sale points. This study has observed that one of the most powerful factors shaping decisions on farming methods takes place at the sales point when monetary resources are paid in cash to farmers. In particular, the coffee crisis in $2001 / 2002$, when coffee prices fell to an extreme low of US\$ 45 cents per pound, had a strong effect on landuse. Coffee farmers, especially those with farms above 5 ha, opted for planting other crops such as sugarcane or keeping livestock. According to generalized farmers' perceptions, the amount of monetary premiums decreased progressively from that time and does not compensate for the low yields of the organic plantations. One of the reiterated comments by farmers is that coffee production is lower on organic than conventional schemes, especially during transition from conventional to organic production.

Other factors with great influence on coffee production (Figure 1, inferior panel) are highlighted as follows: bee and insect pollination has been accounted for a 10.5 $\pm 2.0 \%$ increase $(t=5.36$, d.f. $=111, P<0.001)$ in coffee final fruit set (i.e. the proportion of flowers that resulted in mature fruits [9]. Based on respondents' agro-ecological knowledge, organic and conventional farming differed in agricultural practices that lie well beyond the use of synthetic inputs. Organic schemes involve: the harnessing of soil fertility derived from deposition of leaf litter from diverse shade trees; recycling of organic wastes such as coffee pulp and manure of chicken and cattle; the use of natural minerals (e.g. bone meal, minerals of rock phosphate, sulphate, mined lime and other natural salts with $\mathrm{Ca}, \mathrm{Si})$; and the application of biological control of pests. In terms of shade, organic and conventional coffee farms shared tree species belonging to botanical families inter alia, Fabaceae, Mimosaceae, Myrtaceae, Rutaceae, and Clusiaceae. Tree densities [9] differed on the farms due to organic plots, showing lower ranges (47-392 trees/Ha) than conventional plots (30-630 trees/Ha). Conversely, trees richness was similar on organic (5-50 tree species/ $\mathrm{Ha}$ ) and conventional crops (4-52 tree species/Ha). One of the most important differences between management types lies in the early stage of plant growth on organic plots, which require higher levels of shade cover. This is related to the fact that conventional farmers apply synthetic inputs at this stage to protect plants against the effect of direct sunlight. In contrast, organic farmers have to be immensely careful to make use of more shade cover to satisfy this aim (shade covers on organic: $30-70 \%$ and conventional: $20-50 \%)$.

In general terms, current coffee farmers are from the 45 to 70-year age bracket and most of their children study and contribute little to coffee and agricultural work. Young people generally prefer living in nearby towns or distant cities in order to study or work. Although coffee is one of the most important land-uses, the strategy in the study site is to avoid a dependence on only one crop, while ensuring sustenance and incomes for present and future times. Cassava, maize, plantain, and occasionally livestock can provide additional resources. Sugarcane represents an important, customary land use in the region as it has been an alternative occupation when people are not working on coffee. The role of community organizations is crucial since being part of a collective promotes the adoption and application of agricultural practices, encourages cooperative working, the strengthening of social networks and the sharing of benefits.

In general terms, the coffee area harvested in Colombia is equivalent to 771,728 ha on 2014 [10]. The production of Arabic coffee (Coffea arabica) contributed $7 \%$ to Colombian export earnings for the $2000-2010$ period [11]. Colombia only produces arabica coffee. Coffee farming families are distributed across 588 municipalities of 20 zones at national level [12]. More than 563,000 coffee farming families depend on this crop for their household income, of which $95 \%$ have less than 5 ha [12]. Farmers produce coffee in different shade coffee agroecosystems with variation in vegetation structure. Coffee with moderate shade occupies $40 \%$ of total coffee land in Colombia [13]. A small proportion of coffee is produced organically in Colombia, less than one percent of all coffee grown. Only 164 out of all the 31,000 coffee growers on Santander area have organic certifications $[13,14]$. In line with this, $23.7 \pm 1.7 \%$ of Colombian coffee exported between 2007 and 2012 were specialty coffees with a certification seal, and $68.8 \pm 2.1 \%$ were conventional coffees $[15,16]$. Globally, specialty coffees have been estimated to constitute $8 \%$ of world exports and are perceived as having the potential to grow, thanks to greater consumer interest in this type of coffee [17].

\section{Group of Actors \#2: Processors}

Following Figure 1, processors involve actors who treat coffee through manufacturing process of milling and roasting. FNC has also played a key role processing and trading coffee in the international sphere. There are different processors at local, national and international levels, who actively negotiate their respective interests with each other and with socioeconomic and socio-political actors, whether locally or on broader scale.

From a historic perspective in the world coffee market, the role of roasters is illustrative in the context of instant coffee [18]. Drinkers of instant coffee were concerned with speed and convenience, not the quality of the brew. Thus roasters who captured this market used low-priced beans, especially Robusta beans. African producers (Ivory Coast) and Asia growers, especially in Vietnam and Indonesia, flooded the world market with Robusta. The world coffee market now had two major raw materials and two major price-setting markets: The New York " $\mathrm{C}$ " for Arabica and London for Robusta. This undercut the price of Arabica beans, lowered the overall quality of coffee consumed, and increased returns to ever-larger processors rather than to growers. It also reduced Latin American grower's place in the world market [18].

While a coffee grower earns an average payment of $6.5 \%$ of the total sale on international markets [19], worldwide, in 1998 five multinationals had a 69 percent share of the roasting and instant coffee markets [18]. This trend has been countered by the specialty coffee movement, whose 
profitability has been estimated to increase up to $25 \%$ on farmer earnings for sales of certified coffees to USA and Canada [19]. According to observations of this study with Fair Trade-certified producers, unfortunately for the producer countries, most of the money associated with this trend, not necessarily increases significantly returns to coffee growers. Fair Trade prices are not always significantly higher than conventional market prices and some farmers find the rigorous certification requirements related to FT production unduly burdensome.

\section{Group of Actors \#3: Traders}

Coffee is traded in a multitude of different qualities, varieties and forms. These include arabica and robusta, roasted or green, as well as instant and solubles. Over 70 countries produce coffee, and over 50 percent comes from just three countries (Brazil, Vietnam, Colombia). In 2012, total exports of 7 million tonnes accounted for a value of US\$24 billion [10]. According to the ICA mentioned above, participating growing countries were given annual export quotas to maintain coffee's international price. It maintained a relatively high coffee price and permitted exporting countries to enjoy a substantial share of the final consumer price $[18,20]$. The ICA governed quality standards for most of the coffee industry from 1962 to 1989 [21,22]. The disintegration of the ICA and market liberalization contributed to increasing global coffee production. The increasing coffee supply led to rising inventories in importing/consumer countries and coincided with slow demand and market concentration in the roasting and trading industries [21,23]. The result was ever-greater control of the global market by companies such as Nestle and Procter \& Gamble [18]. The world's five largest roasters bought nearly half of the world's green coffee. Although subsequent agreements were settled, none has had the influence and importance of the first ICA. The seventh was agreed on 2007 aimed at strengthening the ICO's role as a forum for intergovernmental consultations and facilitate international trade [5].

At local level, FNC promoted the entrance of certification seals in many coffee areas. During the coffee crisis in 2001/2002, only "Fair-trade" organic farmers received the highest value of monetary premium to compensate the extremely low price. That allowed investments to improve house conditions and facilitate coffee processes at post-harvest time. It is worth noting that Fair Trade certifications provide a minimum price to farmers (in 2015 this was 170 US cents per pound for organic washed Arabica coffee), and a social premium (20 cents per pound) to farmers' cooperatives [24]. The latter is retained by the farmers' cooperative and invested in social projects according to member preferences. However, this study observed that these premiums did not necessarily translate into higher incomes for farmers selling their 2010/2011 harvest when international prices were considerably higher than a floor price. Profits were below farmer expectations. Therefore, premiums alone do not guarantee increased returns to coffee growers.
In contrast, the 2018 situation is quite different with Colombian coffee prices having fallen from 332.07 US cents/pound on 2 May 2011 to 160 US cents/pound on November $2016[25,26]$. There has been an ongoing reduction in prices from Nov 2016 to August 2018 falling to 97.25 US cents/pound $[12,25]$. The latter has showed the role of speculators and coffee inventories [27] in the network. Inventories are stocks of green coffee held by importers, traders and roasters in importing countries [28]. According to FNC [29], the fact that those inventories are held on consuming countries produces a powerful effect on international prices. Thus the action of speculators was noteworthy in pressing negatively the coffee prices until a value below 100 cents per pound [27]. Furthermore, it is important to note that while worldwide coffee demand has grown at an average annual rate of $2.2 \%$ in the last five years, global output is expected to exceed it by 3.41 million bags in coffee year 2018/19, making this the second consecutive year of surplus. As a result, global coffee prices remain the lowest monthly average of the current coffee year [30].

\section{Conclusion}

While an ever-greater control of the network by a few coffee processing companies seems to be a prevalent trend, coffee farmers face a highly competitive and complex global marketplace in which neither conventional prices nor the benefits of alternative markets like Fair Trade are stable, or even evident. From an institutional perspective, to what extent does the multirole of FNC in growing, processing and trading coffee contribute to unify and potentially reduce net incomes of farmers? In an ideal world aimed at increasing substantially net profits of small coffee growers, there would be no need for intermediaries; farmers could produce, process, roast and market their coffee at local or at international levels by themselves. However, that is not a realistic situation taking account of the production and marketing costs, fluctuating coffee prices, available labor, and access to markets. Other alternative could be trying to reduce the number of intermediaries between farmers and consumers by empowering farmer cooperatives with the purpose of negotiating their coffee directly with traders. Furthermore, ensuring a minimum price of 2 USD per coffee pound [31] was proposed in the recent World Coffee Producers Forum in Brazil (9-12 July 2019).

More than 540,000 Colombian families and 25 million small coffee farmers produce $70 \%$ of the world's coffee [5]. This article has described how they are particularly affected by fluctuations in market prices and imbalances in supply and demand. Economic factors reveal how farmers are involved in trade and market networks on broader spatial scales with multiple forces involved over time in a crop going global. The network displayed two types of connections: firstly, between people who are distant and unfamiliar to each other, with different lifestyles, cultures and contrasting modes of production; secondly, between production, intermediation, processing, marketing, and consumption. Furthermore, it is interesting to highlight how governance of the network moved away 
from the grower to the exporter; to the roaster, governments and institutions in the twentieth century; and today to a few multinational firms.

\section{References}

1. Cronon W (1985) Changes in the land Indians, colonists, and the ecology of New England. Hill and Wang, New York.

2. Guber R (2001) La etnografía método, campo y reflexividad. Grupo Editorial Norma, Bogotá.

3. Handwerker WP (2002) The construct validity of cultures: Cultural diversity, culture theory, and a method for ethnography. American Anthropologist 104: 106-122.

4. Nestel D (1995) Coffee in Mexico: International market, agricultural landscape and ecology. Ecological Economics 15: 165-178.

5. (2018b) International coffee agreement. ICO 2007.

6. Eakin H, Tucker C, Castellanos E (2006) Responding to the coffee crisis: A pilot study of farmers' adaptations in Mexico, Guatemala and Honduras. The Geographical Journal 172: 156-171.

7. Leve L (2011) Identity. Current Anthropology, 52: 513-535.

8. Frank E, Eakin H, López-Carr D (2011) Social identity, perception and motivation in adaptation to climate risk in the coffee sector of Chiapas, Mexico. Global Environmental Change 21: 66-76.

9. Bravo-Monroy L, Tzanopoulos J, Potts SG (2015) Ecological and social drivers of coffee pollination in Santander, Colombia. Agriculture, Ecosystems and Environment 211: 145-154.

10. (2015) FAO Statistical Pocketbook Coffee. Food and agriculture organization of the United Nations, Rome.

11. (2013b) Exporting Countries: Total Production. ICO

12. (2018a) La gente del café. FNC-Federación Nacional de Cafeteros, Colombia.

13. (2012a) Caficultura Sostenible. FNC, LXXVII National Congress of Coffee Growers.

14. (2012b) Caficultura Sostenible. Report of regional committes, LXXVII National Congress of Coffee Growers.

15. Muñoz LG (2012) Caficultura Sostenible. LXXVII Congreso Nacional de Cafeteros 2012, Federación Nacional de Cafeteros de Colombia.
16. Muñoz LG (2011) Caficultura climáticamente inteligente. LXXVI Congreso Nacional de Cafeteros.

17. (2013a) Monthly Coffee Market Report-January 2014, ICO.

18. Topik S (2009) Historicizing commodity chain, five hundred years of the global coffee commodity chain. In: Bair J, Frontiers of commodity chain research. Stanford University Press, I37-62.

19. Guhl A (2008) Café y Cambio del Paisaje en Colombia, 19702005. Fondo Editorial Universidad EAFIT, Banco de la Republica, Medellín, Colombia, 334.

20. Eakin H, Tucker C, Castellanos E (2005) Market shocks and climate variability: The coffee crisis in Mexico, Guatemala, and Honduras. Mountain Research and Development 25: 304-309.

21. Bacon C (2005) Confronting the coffee crisis: Can fair trade, organic, and specialty coffees reduce small-scale farmer vulnerability in Northern Nicaragua? World Development 33: 497-511.

22. Barham BL, Callenes M, Lewis J, Gitter S, Weber J (2011) Fair trade/organic coffee, rural livelihoods, and the "Agrarian Question": Southern Mexican coffee families in transition. World Development 39: 134-145.

23. (2018a) Retail prices of roasted coffee in selected importing countries, ICO.

24. (2018) Fairtrade Minimum price and premium information.

25. (2018b) Medidas cafeteras diarias. Federación Nacional de Cafeteros (FNC).

26. (2018c) Composite and group indicator prices (annual and monthly averages). ICO.

27. (2018c) Gobierno anuncia $\$ 100$ mil millones en apoyos directos al precio interno de café. FNC.

28. (2018d) Glossary of terms used. ICO.

29. (2018d) Brasil y Colombia alertan sobre escenario depredador en el mercado mundial de café. FNC.

30. (2019) Coffee Market Report May 2019. International Coffee Organisation.

31. Velez R (2019) Conference General Manager of FNC. World Coffee Producers Forum, Campinas, Brazil.

DOI: $10.36959 / 973 / 421$

Copyright: (C) 2019 Bravo-Monroy L. This is an open-access article distributed under the terms of the Creative Commons Attribution License, which permits unrestricted use, distribution, and reproduction in any medium, provided the original author and source are credited. 